\title{
Article \\ Fault Calculation Method of Distribution Network Based on Deep Learning
}

\author{
Cong Zhang $\mathbb{D}^{\mathrm{D}}$, Ke Peng *, Huan Li, Bingyin Xu and Yu Chen \\ School of Electrical and Electronic Engineering, Shandong University of Technology, Zibo 266500, China; \\ choolla@live.com (C.Z.); lhsdut17@163.com (H.L.); xuby@sdut.edu.cn (B.X.); chenyu@sdut.edu.cn (Y.C.) \\ * Correspondence: pengke@sdut.edu.cn
}

Citation: Zhang, C.; Peng, K.; Li, H.; $\mathrm{Xu}, \mathrm{B}$;; Chen, Y. Fault Calculation Method of Distribution Network Based on Deep Learning. Symmetry 2021, 13, 1086. https://doi.org/ $10.3390 /$ sym 13061086

Academic Editors: Tomohiro Inagaki

Received: 27 April 2021

Accepted: 15 June 2021

Published: 18 June 2021

Publisher's Note: MDPI stays neutral with regard to jurisdictional claims in published maps and institutional affiliations.

Copyright: (C) 2021 by the authors. Licensee MDPI, Basel, Switzerland. This article is an open access article distributed under the terms and conditions of the Creative Commons Attribution (CC BY) license (https:// creativecommons.org/licenses/by/ $4.0 /)$.

\begin{abstract}
Under the low voltage ride through (LVRT) control strategy, the inverter interfaced distributed generation (IIDG) needs to change the output mode of the inverter according to the voltage of the connected nodes. The short-circuit current is related to the system rated capacity, network short-circuit impedance, and distributed power output. So, based on the deep learning algorithm, a predicting method of the voltage drop is proposed. By predicting the voltage of connected nodes, the output mode of IIDG can be determined based on the LVRT control. Thus, the fault calculation model of IIDG is accurately established. Compared with the three-phase asymmetric Gaussian fault calculation method, the proposed method can achieve fault calculation accurately. Finally, a case study is built to verify the effectiveness of the proposed method. The results indicate that the proposed method can make accurate voltage prediction and improve the computation speed of the fault calculation.
\end{abstract}

Keywords: deep learning; the voltage of connected nodes; inverter interfaced DG; distribution network

\section{Introduction}

The control strategy of inverter interfaced distributed generation (IIDG) has a decisive influence on the characteristics of the fault current, which will become more complicated when considering the low voltage ride through (LVRT) control strategy. According to the requirements of LVRT, the IIDG needs to adjust its control strategy among constant power, fault ride-through, and off-grid. The voltage drop of the connected nodes is different under different control strategies [1]. The level of voltage drop at the connected nodes is related to different fault types and fault locations [2]. In [3], the detailed characteristics of IIDG under different control conditions were analyzed, and the IIDG control output mode can be adjusted to meet LVRT. In the case of system fault, the voltage of the IIDG connected nodes will drop sharply caused by the increase of short-circuit current. At this time, according to the degree of voltage drop the original control mode of IIDG may not meet its LVRT, so different control modes need to be selected. Therefore, the prediction of the degree of voltage drop at the connected nodes, can simplify the fault calculation procedure, by directly providing the control method of the inverter during the fault calculation. However, the different output modes of IIDG under the LVRT control strategy have different supporting effects on the voltage of connected nodes, especially when the IIDG is connected in high density. Due to the control characteristics of IIDG and the distribution of IIDG in distribution network, so it is difficult to build a determined model of the fault current.

The voltage drop problem is well studied in terms of the cause of voltage drop and its propagation characteristics. In the recent research on the voltage drop of a traditional power system, the evaluation method could be divided into two categories: real-time monitoring and random prediction.

(1) The real-time monitoring method is restricted by the monitoring level, so its applications in the power system are restricted [4,5]. In [6], the fault point was regarded 
as a new virtual node. By calculating the self-impedance and mutual impedance between virtual nodes and related nodes, the node impedance matrix of the system was expanded, and short circuit fault is set to analyze voltage sag. In [7], a method for voltage amplitude interval estimation was proposed based on the information of an existing data acquisition system in a low voltage distribution network. In [8], in order to realize the rapid and reasonable prediction of the loss results in the early stage of the event, a voltage sag economic loss prediction model was proposed based on the information distribution and diffusion theory, which used the sag monitoring information.

(2) For the random prediction method of voltage drop, relevant studies mainly focus on the prediction of each node, under the short-circuit fault of the traditional transmission and distribution network. The critical distance method was first proposed by Bollen $[5,6]$. It had the advantages of simple principles and fast calculation speed. The authors in [9] proposed a method of voltage drop prediction for the ring network based on the traditional critical distance method. However, the critical distance method was weak in the randomness, and this method was only suitable for voltage prediction under symmetrical faults in simple networks. The analytical method [10] can make a good assessment of the system voltage drop level under single or multiple faults. However, this method usually ignored the influence of fault impedance, which leaded to poor evaluation accuracy. The authors in $[11,12]$ introduced the probability method to estimate the voltage drop level in detail. This method was based on the characteristics of Monte Carlo simulation, according to a small amount of system component failure probability information.

However, the above methods are aimed at the traditional transmission and distribution network. In the distribution network containing IIDG, the prediction of the voltage drop needs to be further studied.

In traditional fault calculation, IIDG is generally regarded as the source of PQ and brought it into iterative calculation. However, the output characteristics of IIDG are determined by the LVRT control strategy [13]. So, diversification of control schemes adopted by IIDGs leads to the randomness of the fault current [14]. When LVRT is taken into account, the change of control strategy and the output of IIDG need to be considered. Therefore, the influence of LVRT control strategy needs to be considered in the distribution network fault calculation. When the distribution network fails, the magnitude of the fault current and the contribution of IIDG to the fault current need to be accurately analyzed. The fault current of IIDG depends on the control strategy adopted in the case of grid fault $[15,16]$. Moreover, the relationship among ride through time and short-circuit current is studied, and the short-circuit response of IIDG under different fault conditions was analyzed. In [17], a more accurate IIDG current estimation model based on the Gauss-Seidel method that considered the control strategy at the moment of fault was established. Moreover, the authors proposed a novel faulty feeder detection approach which used the zero-sequence current space relative distance. Based on analyzing the effect of reactive power supplied by IIDG to the point of common coupling (PCC) voltage, an adaptive voltage support control strategy was proposed to enhance the fault ride-through capability of IIDG [18]. The authors in [13] developed a fault model of IIDGs within a low-voltage microgrid, including active/reactive power (PQ)-controlled IIDGs and voltage-controlled IIDGs. In [19-22], a control strategy was proposed to improve the LVRT capability, and reduce active power oscillations, which was marked as the most important control objectives of IIDG during unbalanced voltage sags. In [18], the different control strategies of PQ control IIDG were analyzed, and adjustable parameters were introduced into the model to reflect its fault characteristics as comprehensively as possible. However, it was only applicable to the analysis of a single IIDG, and no analysis was made for the grid connection of IIDG. In [23], a more accurate mathematical equivalent model of IIDG considering IIDG control strategy was established, and the profile characteristics of positive sequence voltage at each point of common coupling were studied. On this basis, a real-time fault current contribution estimation algorithm and a new virtual multi terminal current differential protection scheme was proposed. Even if the LVRT control strategy is considered, the 
fault calculation only continuously corrects the output of IIDG and incorporate it into the iteration. The output mode of LVRT control was not considered, which is given by the prediction of the voltage of the connected nodes.

Due to the uncertainty of its output, new energy power generation will have a significant impact on the stability of power grid when it is connected to the grid in highpermeability [24]. For the deep learning application in distribution network, the authors in [25] proposed a new prediction framework based on $\mathrm{RNN}$ which has better performances when predicting via various time level. Reference [26] proposed a method using DBN to forecast the output of wind power, and accuracy improvement was achieved. In [27], a stacked denoising method was proposed to forecast wind power, and the bat algorithm was used to determine the hyper-parameters of network.

The main contributions of this paper to the research field are as follows.

(1) A forecasting method of the connected nodes voltage is proposed based on the deep learning method. By appropriate and simulation data, BP (back propagation) neural network algorithm is applied to establish the relationship among the connected node voltage, system rated capacity, network short-circuits impedance and distributed power output.

(2) Based on the proposed forecasting method, in order to achieve LVRT, a fault calculation method is proposed based on the prediction of the voltage of connected nodes. Compared with the traditional methods, the output mode of IIDG can be identified based on the voltage drop. In order to achieve LVRT, the output of IIDG can be determined. So, calculation speed is improved.

(3) Based the IEEE 13 system, a study case is built to verify the effectiveness of the proposed methods. Comparing the simulation results of DIgSILENT, the proposed method can realize the accurate calculation of the voltage drop and fault calculation.

(4) The structure of this paper is as follows. Section 2 analyses the connected nodes voltage under different working conditions. Section 3 introduces the method of voltage prediction based on deep learning. The effectiveness of the proposed method is verified in Section 4. Section 5 concludes the paper.

\section{Analysis of Connected Nodes Voltage under Different Working Conditions}

In the fault calculation of the distribution network, the output mode of LVRT control needs to be given according to the degree of voltage drop at the connected nodes. The traditional fault calculation method of LVRT requires to correct the output power of IIDG iteratively according to the voltage of the connected nodes, which is quite complicated.

As shown in Figure 1, the voltage of the connected nodes can be expressed as:

$$
U_{P C C}=I_{\mathrm{f}} \cdot Z=\left(I_{\mathrm{S}}+I_{\mathrm{IIDG}}\right) Z=\left(\frac{E}{Z_{\mathrm{net}}+Z_{1}+Z_{2}+Z_{\mathrm{flt}}}+I_{\mathrm{IIDG}}\right) Z
$$

where $U_{P C C}$ is the voltage of the IIDG connected nodes and $Z$ is the equivalent impedance from the connected nodes to the short-circuit point.

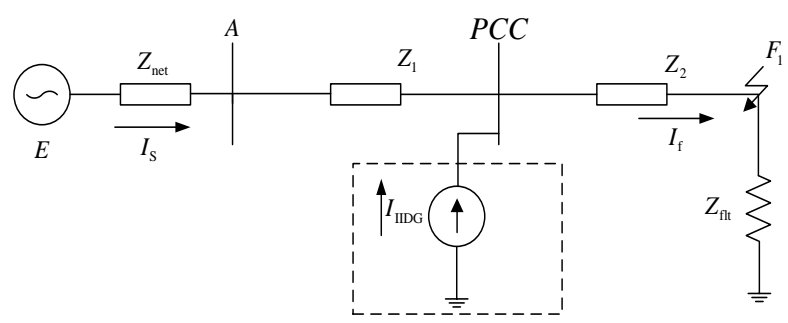

Figure 1. Distribution network diagram with IIDG.

According to Equation (1), it can be seen that the voltage of connected nodes is related to the equivalent impedance of the system, the short-circuit impedance, and the short- 
circuit current provided by IIDG. The equivalent impedance of the system is related to the rated capacity of the system. Generally, the higher the system capacity is, the lower the equivalent impedance of the system will be, and the higher voltage of connected nodes will be. The higher the short circuit impedance of the system is, the lower the voltage of connected nodes will be. The higher the current provided by IIDG is, the higher the voltage of connected nodes will be. Therefore, the voltage of connected nodes is related to the capacity of the system, the system short-circuit impedance, and the output of IIDG. Accordingly, this paper proposes to use the relationships between the system rated capacity, system short-circuit impedance, IIDG output, and the voltage of the connected nodes to estimate the voltage. Thus, the IIDG output mode can be precisely determined.

\section{Voltage Prediction Based on Deep Learning}

\subsection{BP Neural Network Algorithm}

The BP neural network is a kind of multi-layer feedforward neural network, which is characterized as forward propagating the signal and back propagating the error. During the forward propagation, the input is processed layer by layer from the input layer, through the hidden layer, and the output layer. The neurons in the next layer are only related to the state of neurons in forward layer. If the output of the output layer does not meet expectations, it will switch to back propagation, and adjust the weights of the network based on the prediction error, until the predicted output of the BP neural network will continuously approach the expected output. This section introduces the single-hidden layer BP neural network algorithm as an example, and its topology is shown in Figure 2.

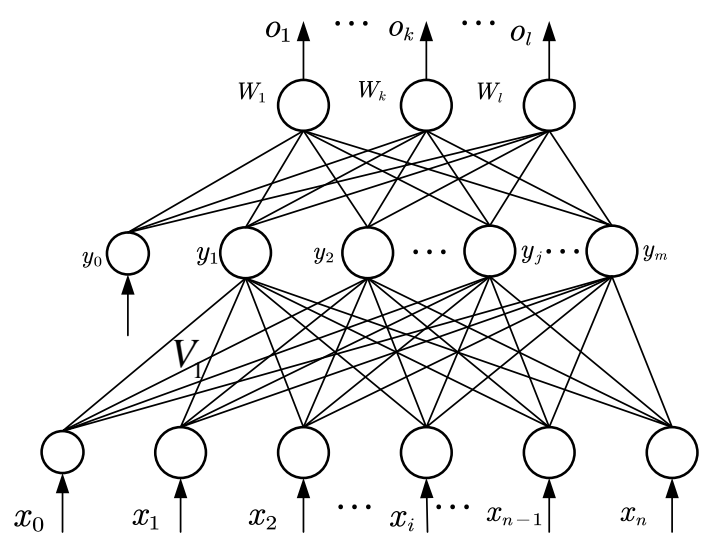

Figure 2. Topological structure of BP neural network.

The input vector in Figure 2 is $X=\left(x_{1}, \ldots, x_{i}, \ldots, x_{n}\right)^{T}$. The output vector of hidden layer is $Y=\left(y_{1}, \ldots, y_{m}\right)^{T}$. The output vector of the output layer is $\mathrm{O}=(\mathrm{o} 1, \mathrm{o} 2, \ldots, \mathrm{ok}, \ldots$, $\mathrm{ol})^{T}$. The expected output vector is $d=\left(d_{1}, d_{2}, \ldots, d_{k}, \ldots, d_{l}\right)^{\mathrm{T}}$. The weight between the input layer and the hidden layer is represented by matrix $V, V=\left(V_{1}, V_{2}, \ldots, V_{j}, \ldots, V_{m}\right)^{T}$, where $V_{j}$ is the weight vector corresponding to the jth iteration neuron in the hidden layer. The weight between the hidden layer and the output layer is represented by matrix $W$, $W=\left(W_{1}, W_{2}, \ldots, W_{k}, \ldots, W_{l}\right)^{T}$, where $W_{k}$ is the weight vector corresponding to the kth neuron in the output layer. For the single hidden layer BP algorithm shown in Figure 2, the relationship between the signals of each layer is as follows:

For the output layer:

$$
\begin{aligned}
o_{\mathrm{k}} & =f\left(\text { net }_{\mathrm{k}}\right) k=1,2, \cdots, l \\
n e t_{\mathrm{k}} & =\sum_{j=0}^{m} w_{\mathrm{jk}} y_{\mathrm{j}} k=1,2, \cdots, l
\end{aligned}
$$

For the hidden layer:

$$
y_{\mathrm{j}}=f\left(n e t_{\mathrm{j}}\right) j=1,2, \cdots, m
$$




$$
n e t_{\mathrm{j}}=\sum_{i=0}^{n} v_{\mathrm{ij}} x_{\mathrm{i}} j=1,2, \cdots, m
$$

In Equations (2) and (4), the activation function can adopt unipolar sigmoid function, bipolar sigmoid function, or linear function as required.

When the network output is not equal to the expected output, there is an output error $E$, which is defined as follows:

$$
E=\frac{1}{2} \sum_{k=1}^{l}\left\{d_{k}-f\left[\sum_{j=0}^{m} w_{\mathrm{jk}} f\left(n e t_{\mathrm{j}}\right)\right]\right\}^{2}=\frac{1}{2} \sum_{k=1}^{l}\left\{d_{\mathrm{k}}-f\left[\sum_{j=0}^{m} w_{\mathrm{jk}} f\left(\sum_{i=0}^{n} v_{\mathrm{ij}} x_{\mathrm{i}}\right)\right]\right\}^{2}
$$

It can be seen from Equation (6) that the network output error is a function that depends on the weights $w_{\mathrm{jk}}$ and $v_{\mathrm{ij}}$ of each layer. So, reasonable weights can satisfy the requirement of error.

Obviously, more specific calculation formulas for weight adjustment are required when performing error adjustment, as shown below:

$$
\left\{\begin{array}{c}
\Delta w_{\mathrm{jk}}=\eta \delta_{\mathrm{k}}^{\mathrm{o}} y_{j}=\eta\left(d_{\mathrm{k}}-o_{\mathrm{k}}\right) o_{\mathrm{k}}\left(1-o_{\mathrm{k}}\right) y_{\mathrm{j}} \\
\Delta v_{\mathrm{ij}}=\eta \delta_{\mathrm{j}}^{\mathrm{y}} x_{\mathrm{i}}=\eta\left(\sum_{k=1}^{l} \delta_{\mathrm{k}}^{\mathrm{o}} w_{\mathrm{jk}}\right) y_{\mathrm{j}}\left(1-y_{\mathrm{j}}\right) x_{\mathrm{i}}
\end{array}\right.
$$

where, $\delta_{\mathrm{k}}^{\mathrm{o}}$ and $\delta_{\mathrm{j}}^{\mathrm{y}}$ are the error signals of the output layer and the hidden layer respectively and $\eta$ is the learning rate, which is within $(0,1]$.

The larger the learning rate $\eta$ is, the larger the weight adjustment will be, and the faster network learning will be. However, too large a learning rate $\eta$ will cause overfitting, while too small a learning efficiency $\eta$ will slow the convergence in the learning process and make the prediction result difficult to stabilize. The variable learning rate method could be exploited in BP neural network to ameliorate the impact of the too small or too large learning rate on the training process. To realize this, the learning rate $\eta$ at the beginning of the training is relatively large, making the training process converge quickly. In the following iterations, $\eta$ keeps decreasing, making sure the calculation is stable. The formula for calculating the learning rate is as follows:

$$
\eta(i)=\eta_{\max }-i \cdot\left(\eta_{\max }-\eta_{\min }\right) / i_{\max }
$$

In Equation (8), $\eta_{\max }$ is the maximum learning rate; $\eta_{\min }$ is the minimum learning rate; $i_{\max }$ is the maximum number of iterations; $i$ represents the $i$-th iteration of the training process.

Generally, it is necessary to normalize the training data in the training process. The purpose of the data normalization process is dimensionless treatment, by different processing methods. There are mainly two methods for data normalization:

(1) Maximum and minimum method, which is as follows:

$$
x_{\mathrm{k}}=\left(x_{\mathrm{k}}-x_{\min }\right) /\left(x_{\max }-x_{\min }\right)
$$

where $x_{\min }$ is the smallest value of the data; $x_{\max }$ is the largest value. Further, by the data normalization process, all data are redefined between $[0,1]$.

(2) Mean-variance method, which is as follows:

$$
x_{\mathrm{k}}=\left(x_{\mathrm{k}}-x_{\text {mean }}\right) / x_{\mathrm{var}}
$$

where $x_{\text {mean }}$ is the mean value of the samples for each variable; $x_{\mathrm{var}}$ is the variance of the data series. 
The predicted results are normalized. So, in order to get the original data, it is also necessary to de-normalize the predicted output data. The de-normalization process is opposite to the normalization process.

Due to the current-limiting characteristics of IIDG, the output short-circuit current may be limited. Therefore, the voltage drop mainly depends on the rated capacity of the system and the system short-circuit impedance at the time of failure. The data of system rated capacity, system short-circuit impedance, IIDG output, and the voltage of connected nodes are imported to software MATLAB 2020a, and trained by BP neural network algorithm. Finally, if the error of the estimated results is allowable, the estimated value will be printed. This process is shown in Figure 3.

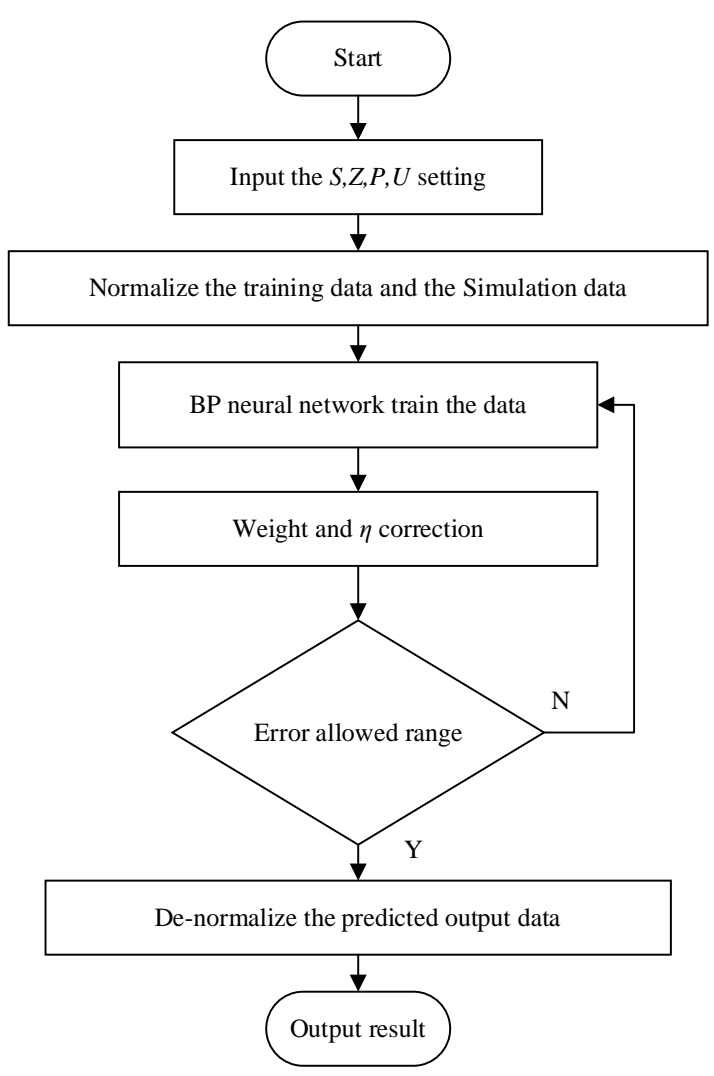

Figure 3. Flow chart of voltage prediction of connected nodes based on deep learning.

\subsection{Calculation of Distribution Network Faults Considering Voltage Prediction}

In traditional fault calculation, IIDG is generally regarded as the source of PQ. Even if the LVRT control strategy is considered, the fault calculation only continuously corrects the output of IIDG and incorporates it into the iteration, without considering the output mode of the LVRT control through the prediction of the voltage of the connected nodes. The output characteristics of IIDG are determined by the LVRT control strategy. When the system needs to meet LVRT, the change of control strategy and the output of IIDG need to be considered. Therefore, the influence of LVRT control strategy of IIDG needs to be considered in the fault calculation. So, when the distribution network fails, considering the contribution of IIDG the magnitude of the fault current need to be accurately analyzed.

Although the different types of IIDG have different LVRT specifications, their control strategies with LVRT are similar. When the distribution network fails, the voltage magnitude is used as reference variable to determine whether the IIDG enters the LVRT mode. Then, the reference value of the reactive current is calculated and the output reactive power of the IIDG adjusted. Moreover, the reference value of the active and reactive currents of the inverter in LVRT mode is then given by the predicted voltage of connected nodes. Thereby, the calculation speed is increased. 
The node voltage equation of the distribution network after a three-phase short circuit is:

$$
\dot{I}_{\mathrm{f}}=Y_{\mathrm{f}} * \dot{U}_{\mathrm{n}}
$$

At the $k$-th iteration, the three-phase injection current at each node is:

$$
\dot{I}_{\mathrm{i}}=\frac{P_{\mathrm{i}}+j Q_{\mathrm{i}}}{\dot{U}_{\mathrm{i}}}
$$

At the $k+1$-th iteration, the three-phase injection current of each node is:

$$
\stackrel{\bullet}{I_{\mathrm{i} . \mathrm{k}+1}}=Y_{\mathrm{f}} * \dot{U}_{\mathrm{i}}
$$

Based on the above three-phases asymmetric distribution network fault calculation method, the voltage prediction method of connected nodes is proposed to provide a more accurate output mode for the LVRT control of IIDG. The specific calculation steps are as follows:

1. Calculate the voltage of each connected node and determine the output mode of IIDG under the control of LVRT. In this calculation process, IIDG is regarded as the PQ source.

2. Calculate the node admittance matrix $Y_{f}$ of the distribution network.

3. Get the initial voltage value $U_{0}$ and phase angle $\theta_{0}$ at each node of the distribution network.

4. Calculate the injection current $I_{i}$ at each node.

5. Calculate the node voltage $U_{i k}$ at kth iterations by $I_{i}=Y_{f}^{*} U_{i}$.

6. Calculate the $k+1$-th injection current by $I_{i . k}+1=(P+j Q) / U_{i . k}$.

7. Judge whether the corresponding voltage magnitude of the two adjacent iterations meet the convergence condition, $|\Delta U| \leq \varepsilon$. If it meets, the calculation is done. Otherwise, repeat steps 4-6.

According to the flow chart above, the flow chart of fault calculation of distribution network considering LVRT is shown in Figure 4.

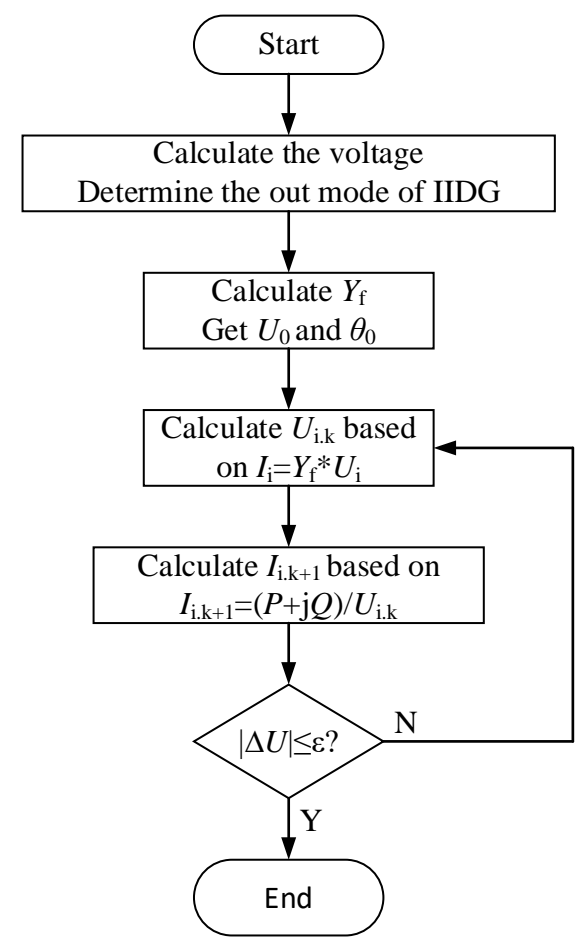

Figure 4. Flow chart of distribution network fault calculation considering LVRT. 


\section{Case Analysis}

The DIgSILENT/PowerFactroy 15.2 simulation software is used to build a 13-node system with a voltage level of $10.5 \mathrm{kV}$ in this paper, as shown in Figure 5, and the specific parameters shown in Table 1. The parameter specifications are shown in Table 1. The data of voltage, system rated capacity, system short-circuit impedance, and IIDG output are collected. Bus 4, 8, and 10 are the IIDG connected nodes. The simulated data are imported into MATLAB and trained by multi-hidden-layer BP neural network algorithm to predict the voltage of connected nodes in different situations. The correctness and effectiveness of the proposed method is verified. The input data, expected output data, predictive output, and other data have been normalized using Equation (8) before the training, in order to improve the accuracy of model prediction and the speed of convergence.

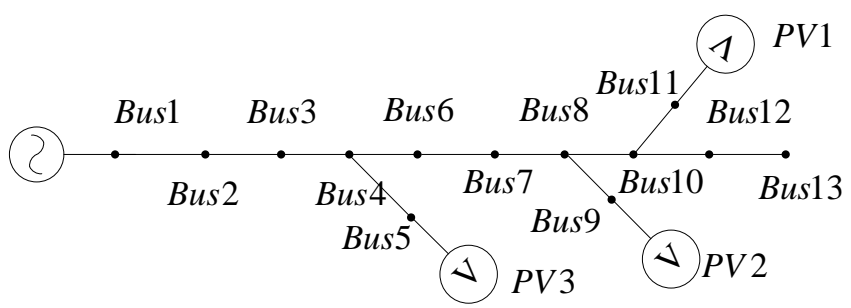

Figure 5. IEEE 13 bus system diagram with IIDG.

Table 1. Line Parameters.

\begin{tabular}{ccccc}
\hline Branch & from Bus & to Bus & $\mathbf{R}(\boldsymbol{\Omega})$ & $\mathbf{X}(\mathbf{H})$ \\
\hline Line 1 & 1 & 2 & 0.0922 & 0.0477 \\
Line 2 & 2 & 3 & 0.493 & 0.2511 \\
Line 3 & 3 & 4 & 0.366 & 0.1864 \\
Line 4 & 4 & 6 & 0.3811 & 0.1941 \\
Line 5 & 6 & 7 & 0.319 & 0.107 \\
Line 6 & 7 & 8 & 0.7114 & 0.2351 \\
Line 7 & 8 & 10 & 0.703 & 0.340 \\
Line 8 & 10 & 12 & 0.3744 & 0.1238 \\
Line 9 & 12 & 13 & 0.468 & 0.155 \\
Line 10 & 4 & 5 & 0.0112 & 0.0086 \\
Line 11 & 7 & 9 & 0.0112 & 0.0086 \\
Line 12 & 8 & 11 & 0.0112 & 0.0086 \\
\hline
\end{tabular}

This paper focuses on the prediction of the voltage of connected nodes, under different three-phase short-circuit conditions. Due to the current-limiting effect of the inverter, the voltage drop depends on the rated capacity and the short-circuit impedance. So, the power output of IIDG is added to meet the requirement of the setting value to improve the accuracy of the prediction.

\subsection{The Relationship between S, Z, P, and the Voltage of the Connected Nodes}

By analyzing the relationship among the rated capacity, short-circuit impedance, and the voltage of the connected node, the activation function of the BP neural network algorithm is determined. Moreover, the output mode of LVRT is accurately selected by the predicted voltage when the distribution network fails. Thus, the speed of the fault calculation is improved.

The short-circuit node in the aforementioned simulation is Bus 13. With constant system short-circuit impedance and IIDG output, the voltages at three connected nodes, under different system rated capacity are simulated and presented in Table 2. In order to more intuitively express the rule of the voltage of connected nodes changing with the rated capacity of the system, the simulated data are also visualized in Figure 6. 
Table 2. Simulation data of system rated capacity and UPCC.

\begin{tabular}{|c|c|c|c|c|c|c|c|}
\hline $\begin{array}{l}\text { System Rated } \\
\text { Capacity } \\
\text { (MVA) }\end{array}$ & $\begin{array}{c}\text { The Voltage of } \\
\text { Node } 4(\mathrm{kV})\end{array}$ & $\begin{array}{c}\text { The Voltage of } \\
\text { Node } 8(\mathrm{kV})\end{array}$ & $\begin{array}{l}\text { The Voltage of } \\
\text { Node } 10(\mathrm{kV})\end{array}$ & $\begin{array}{c}\text { System Rated } \\
\text { Capacity } \\
\text { (MVA) }\end{array}$ & $\begin{array}{c}\text { The Voltage of } \\
\text { Node } 4(\mathrm{kV})\end{array}$ & $\begin{array}{c}\text { The Voltage of } \\
\text { Node } 8(\mathrm{kV})\end{array}$ & $\begin{array}{l}\text { The Voltage of } \\
\text { Node } 10(\mathrm{kV})\end{array}$ \\
\hline 150 & 7.26843 & 3.9248 & 2.14587 & 205 & 7.45517 & 4.03003 & 2.19529 \\
\hline 155 & 7.29079 & 3.9362 & 2.15179 & 210 & 7.46734 & 4.02624 & 2.19852 \\
\hline 160 & 7.31178 & 3.9469 & 2.15734 & 215 & 7.47894 & 4.03216 & 2.2016 \\
\hline 165 & 7.3315 & 3.95696 & 2.16256 & 220 & 7.49002 & 4.03782 & 2.20453 \\
\hline 170 & 7.35012 & 3.96645 & 2.16748 & 225 & 7.50061 & 4.04323 & 2.20734 \\
\hline 175 & 7.36767 & 3.9754 & 2.17213 & 230 & 7.51074 & 4.0484 & 2.21003 \\
\hline 180 & 7.38426 & 3.98386 & 2.17652 & 235 & 7.5202 & 4.05335 & 2.2126 \\
\hline 185 & 7.39905 & 3.99186 & 2.18067 & 240 & 7.52974 & 4.0581 & 2.21507 \\
\hline 190 & 7.41484 & 3.99945 & 2.18461 & 245 & 7.53866 & 4.06265 & 2.21744 \\
\hline 195 & 7.42897 & 4.00666 & 2.18835 & 250 & 7.54715 & 4.06702 & 2.21971 \\
\hline 200 & 7.44239 & 4.01351 & 2.19191 & & & & \\
\hline
\end{tabular}

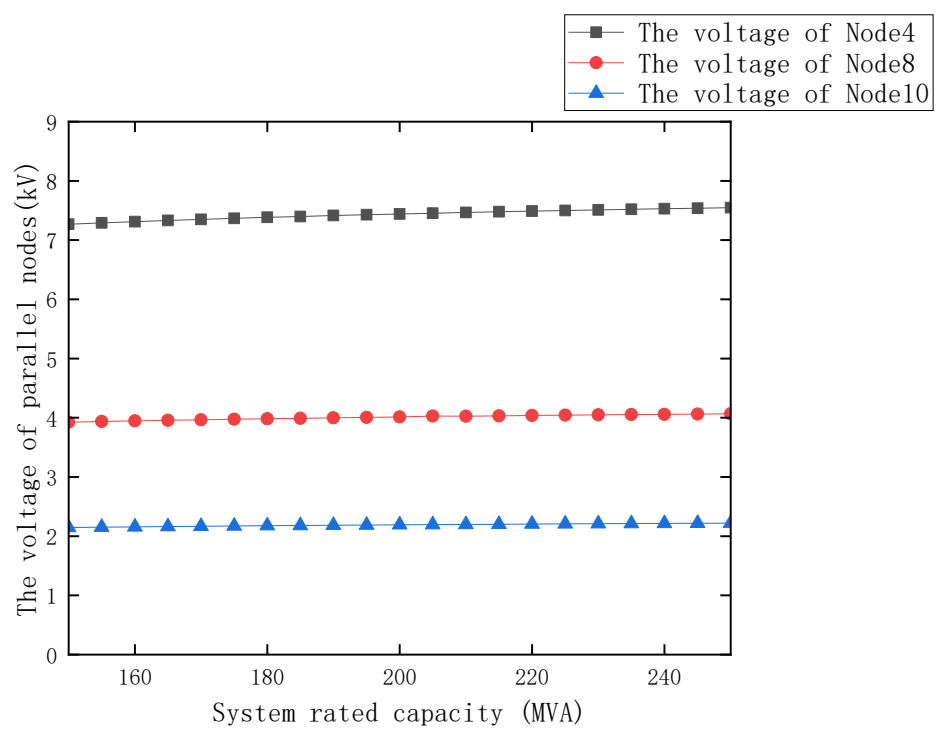

Figure 6. The regular chart of UPCC changing with rated capacity of the system.

It can be seen from the results shown in Table 2 and Figure 6 that, with the increasing of the system rated capacity, the voltages of IIDG connected nodes also increase when system short-circuit impedance and the IIDG output are constant.

Keeping system rated capacity and IIDG output constant, the voltages of all connected nodes, with different system short-circuit impedance, are simulated and recorded, which are shown in Table 3 and visualized in Figure 7.

Table 3. Simulation data of short circuit impedance and UPCC.

\begin{tabular}{|c|c|c|c|c|c|c|c|}
\hline $\begin{array}{c}\text { The Short } \\
\text { Circuit } \\
\text { Impedance } \\
(\Omega)\end{array}$ & $\begin{array}{l}\text { The Voltage of } \\
\text { Node4 (kV) }\end{array}$ & $\begin{array}{c}\text { The Voltage of } \\
\text { Node8 }(\mathbf{k V})\end{array}$ & $\begin{array}{c}\text { The Voltage of } \\
\text { Node10 (kV) }\end{array}$ & $\begin{array}{l}\text { The Short } \\
\text { Circuit } \\
\text { Impedance } \\
(\Omega)\end{array}$ & $\begin{array}{c}\text { The Voltage of } \\
\text { Node4 }(\mathbf{k V})\end{array}$ & $\begin{array}{c}\text { The Voltage of } \\
\text { Node8 }(\mathrm{kV})\end{array}$ & $\begin{array}{c}\text { The Voltage of } \\
\text { Node10 (kV) }\end{array}$ \\
\hline 4.23833713 & 7.86014 & 4.22706 & 2.3309 & 4.39390062 & 7.94175 & 4.43251 & 2.56791 \\
\hline 4.25247927 & 7.86772 & 4.24615 & 2.32748 & 4.40804276 & 7.94897 & 4.45067 & 2.59153 \\
\hline 4.2666214 & 7.87527 & 4.26516 & 2.35181 & 4.42218489 & 7.95616 & 4.46875 & 2.61506 \\
\hline 4.29029865 & 7.88278 & 4.2841 & 2.3761 & 4.43632703 & 7.96332 & 4.48675 & 2.6385 \\
\hline 4.29490567 & 7.89027 & 4.30295 & 2.40034 & 4.45046916 & 7.97045 & 4.50466 & 2.66185 \\
\hline 4.30904781 & 7.89773 & 4.32172 & 2.4245 & 4.4646113 & 7.97754 & 4.52249 & 2.68512 \\
\hline 4.32318994 & 7.90515 & 4.3404 & 2.4486 & 4.47875344 & 7.98461 & 4.54024 & 2.7083 \\
\hline 4.33733208 & 7.91254 & 4.35889 & 2.47262 & 4.49289557 & 7.99165 & 4.5579 & 2.73138 \\
\hline 4.35147421 & 7.91898 & 4.3775 & 2.49657 & 4.50703771 & 7.99865 & 4.57549 & 2.75438 \\
\hline 4.36561635 & 7.92721 & 4.39592 & 2.52043 & 4.52117984 & 8.00563 & 4.59299 & 2.77727 \\
\hline 4.37975849 & 7.9345 & 4.41426 & 2.54421 & & & & \\
\hline
\end{tabular}




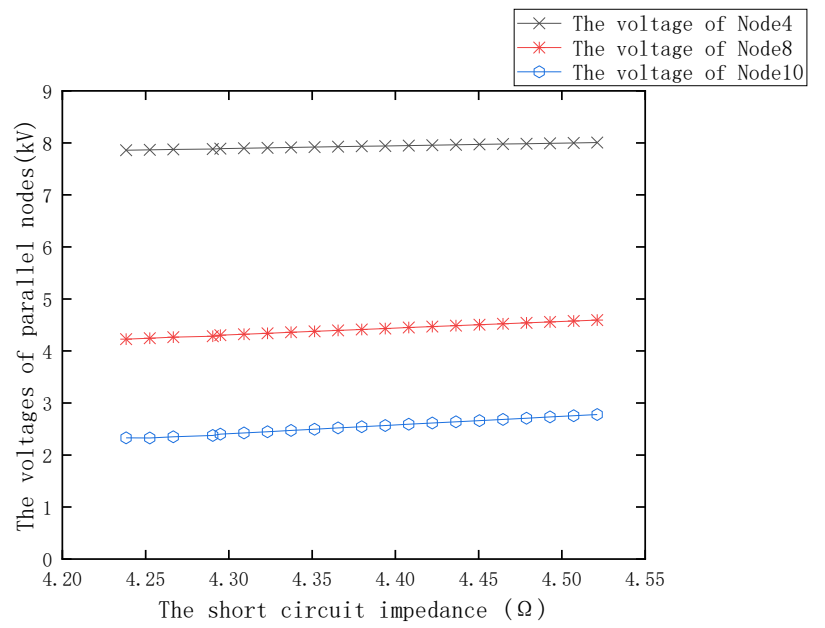

Figure 7. The regular chart of UPCC changing with short circuit impedance.

It can be seen from Table 3 and Figure 7, with the increasing of the system short-circuit impedance, the voltages of connected nodes also increase when the system rated capacity and IIDG output are constant.

Keeping system rated capacity and short-circuit impedance constant, the voltages at the three connected nodes with different IIDG outputs are simulated and recorded, which are shown in Table 4 and Figure 8.

Table 4. Simulation data of UPCC and power of IIDG.

\begin{tabular}{|c|c|c|c|c|c|c|c|}
\hline $\begin{array}{c}\text { Power of } \\
\text { IIDG (MW) }\end{array}$ & $\begin{array}{c}\text { The Voltage of } \\
\text { Node } 4(\mathrm{kV})\end{array}$ & $\begin{array}{c}\text { The Voltage of } \\
\text { Node } 8(\mathrm{kV})\end{array}$ & $\begin{array}{c}\text { The Voltage of } \\
\text { Node10 (kV) }\end{array}$ & $\begin{array}{c}\text { Power of } \\
\text { IIDG (MW) }\end{array}$ & $\begin{array}{c}\text { The Voltage of } \\
\text { Node4 (kV) }\end{array}$ & $\begin{array}{c}\text { The Voltage of } \\
\text { Node8 }(\mathbf{k V})\end{array}$ & $\begin{array}{c}\text { The Voltage of } \\
\text { Node10 (kV) }\end{array}$ \\
\hline 0.3 & 7.78824 & 4.12042 & 2.21366 & 1.754 & 7.91482 & 4.33809 & 2.38537 \\
\hline 0.45 & 7.80192 & 4.14529 & 2.23533 & 1.856 & 7.92332 & 4.35066 & 2.39208 \\
\hline 0.6 & 7.81542 & 4.16979 & 2.25663 & 1.957 & 7.93178 & 4.36316 & 2.39874 \\
\hline 0.75 & 7.82876 & 4.19394 & 2.2776 & 2.058 & 7.9402 & 4.3756 & 2.40537 \\
\hline 0.9 & 7.84193 & 4.21774 & 2.29823 & 2.144 & 7.9474 & 4.38499 & 2.41038 \\
\hline 1.05 & 7.85494 & 4.24121 & 2.31885 & 2.195 & 7.95181 & 4.3873 & 2.41161 \\
\hline 1.2 & 7.8678 & 4.26436 & 2.33856 & 2.246 & 7.95622 & 4.38961 & 2.41285 \\
\hline 1.35 & 7.88015 & 4.28719 & 2.35826 & 2.296 & 7.96062 & 4.39192 & 2.41408 \\
\hline 1.45 & 7.88914 & 4.30001 & 2.36508 & 2.347 & 7.96526 & 4.39423 & 2.41532 \\
\hline 1.552 & 7.89774 & 4.31227 & 2.37188 & 2.398 & 7.96941 & 4.39654 & 2.41665 \\
\hline 1.653 & 7.9063 & 4.32546 & 2.37864 & & & & \\
\hline
\end{tabular}

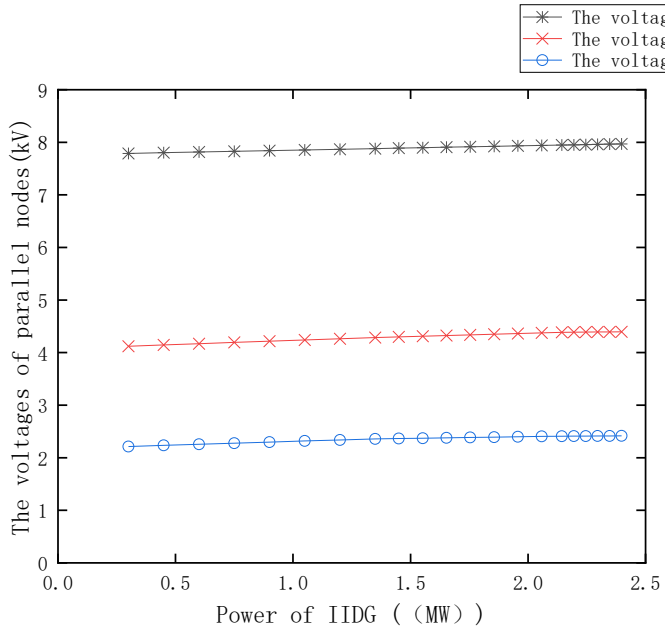

Figure 8. The regular chart of UPCC changing with power of IIDG. 
It can be seen from Table 4 and Figure 8 that, with the increasing of the IIDG output. the connected nodes voltages also increase when the system rated capacity short-circuit impedance of the system are constant. From Table 4 and Figure 6, it could be concluded that the inverter outputs at different locations are not the same with the increase of IIDG output. The closer the IIDG is to the short-circuit point, the easier its output is to reach the threshold. Moreover, the increase of the voltage of the connected nodes is not obvious.

It can be seen from Figures 6-8 that, under the independent action of the system rated capacity, network short-circuits impedance, and IIDG output, there is an approximate positive or negative correlation with the corresponding voltage of connected nodes. Among them, the rated capacity of the system is approximately proportional to the voltage of the IIDG connected nodes. The relationship between system short-circuit impedance and the voltage of connected nodes is approximately proportional. The IIDG output will raise the voltage of connected nodes, and its relationship with the voltage of connected nodes is approximately proportional.

It can be seen from Figures $6-8$ that the voltage of the connected nodes is approximately proportional with the rated capacity of the system, the short circuit impedance and the IIDG output. So, the BP neural network with double hidden-layer is applied to achieve the voltage prediction. The input of the neural network is the rated capacity of the system, the short circuit impedance and the IIDG output. Moreover, the output of the neural network is the voltage.

\subsection{Analysis of Connected Nodes Voltage Prediction}

In this paper, the normalization of the BP neural network function is realized using Equation (9), and the purelin function is used as the activation function. Through 21 groups of data for deep learning, the voltages at connected nodes under different short-circuit conditions are predicted. First, the voltages at the connected nodes are predicted when three-phase short -circuit occurs at Bus6. Since IIDG2 and IIDG3 are located downstream of the short-circuit point, the voltages of the connected node 2 and node 3 will not be predicted. The predicted results of node 1 are shown in Figure 9. Then, the voltages at connected nodes are predicted when three-phase short-circuit occurs at Bus12, which are shown in Figures 10-12. In these figures, the black solid line represents the predicted voltages of connected nodes, using deep learning method, and the blue dotted line represents the simulated voltages of connected nodes. The errors between prediction and simulation results are shown in Figure 13.

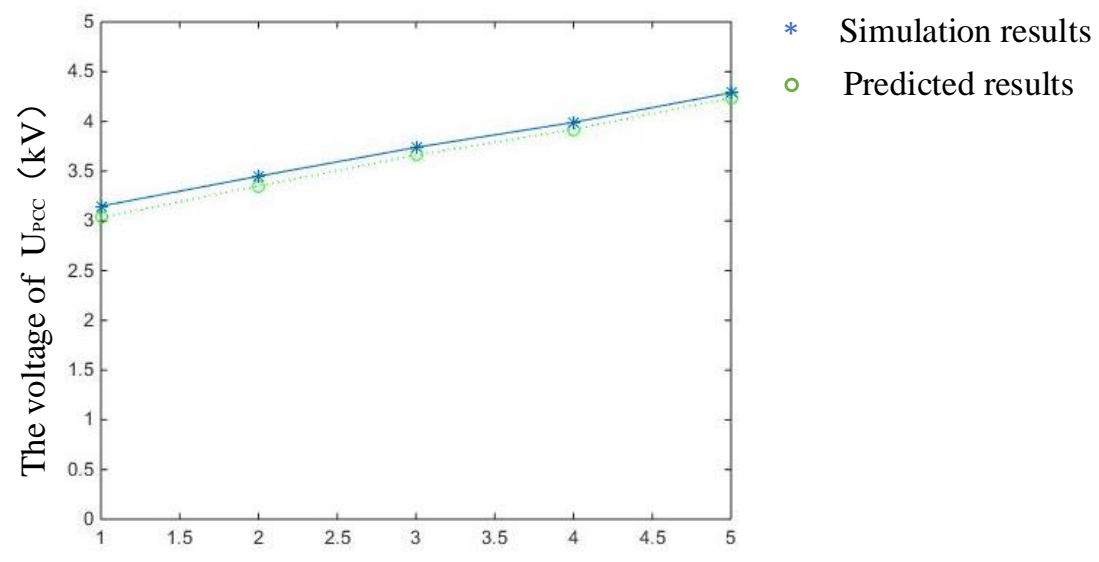

Figure 9. The voltage of $U_{P C C}$ when three-phase short circuit occurs at Bus6. 


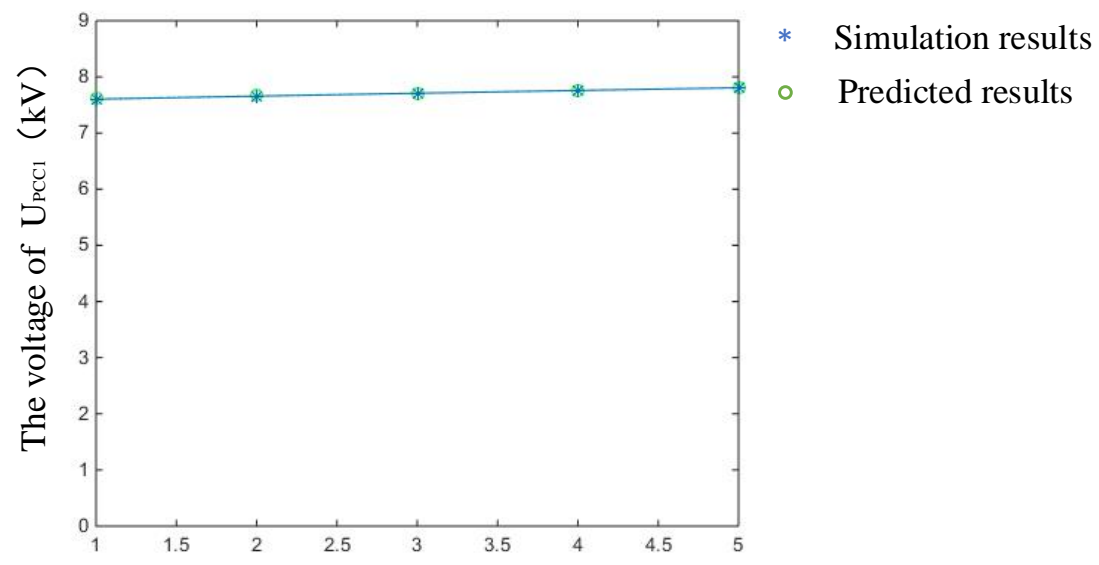

Figure 10. The voltage of $U_{P C C 1}$ when three-phase short circuit occurs at Bus12.

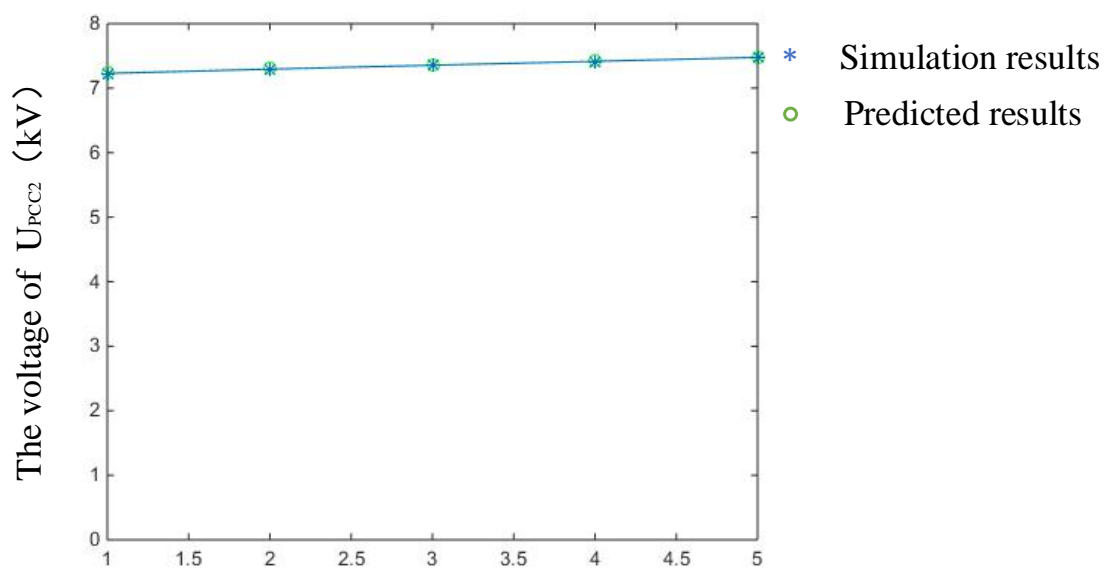

Figure 11. The voltage of $\mathrm{U}_{\mathrm{PCC} 2}$ when three-phase short circuit occurs at Bus11.

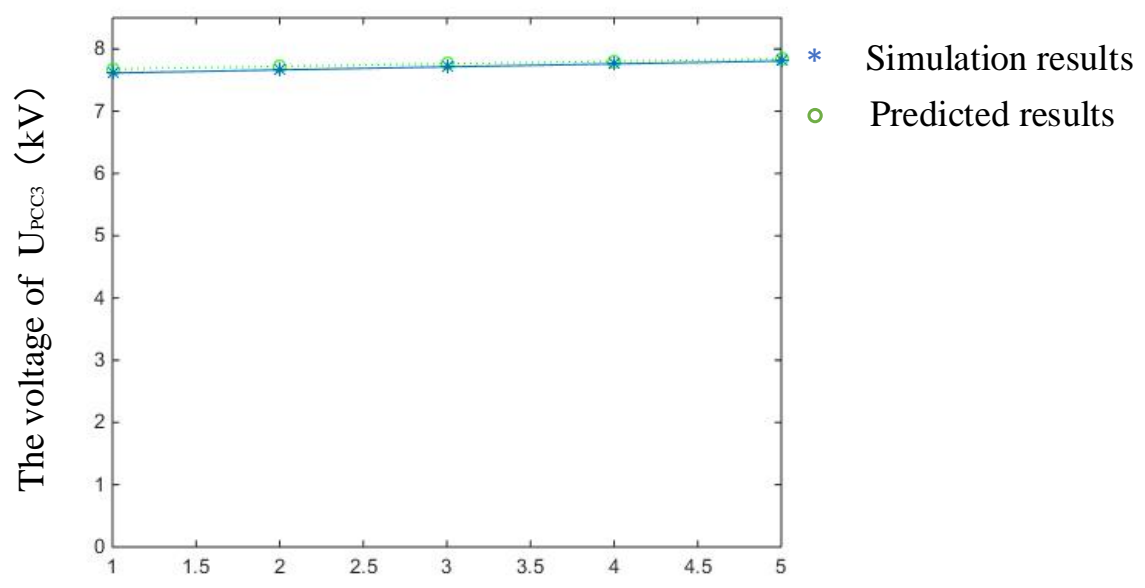

Figure 12. The voltage of $U_{\mathrm{PCC} 3}$ when three-phase short circuit occurs at Bus12. 

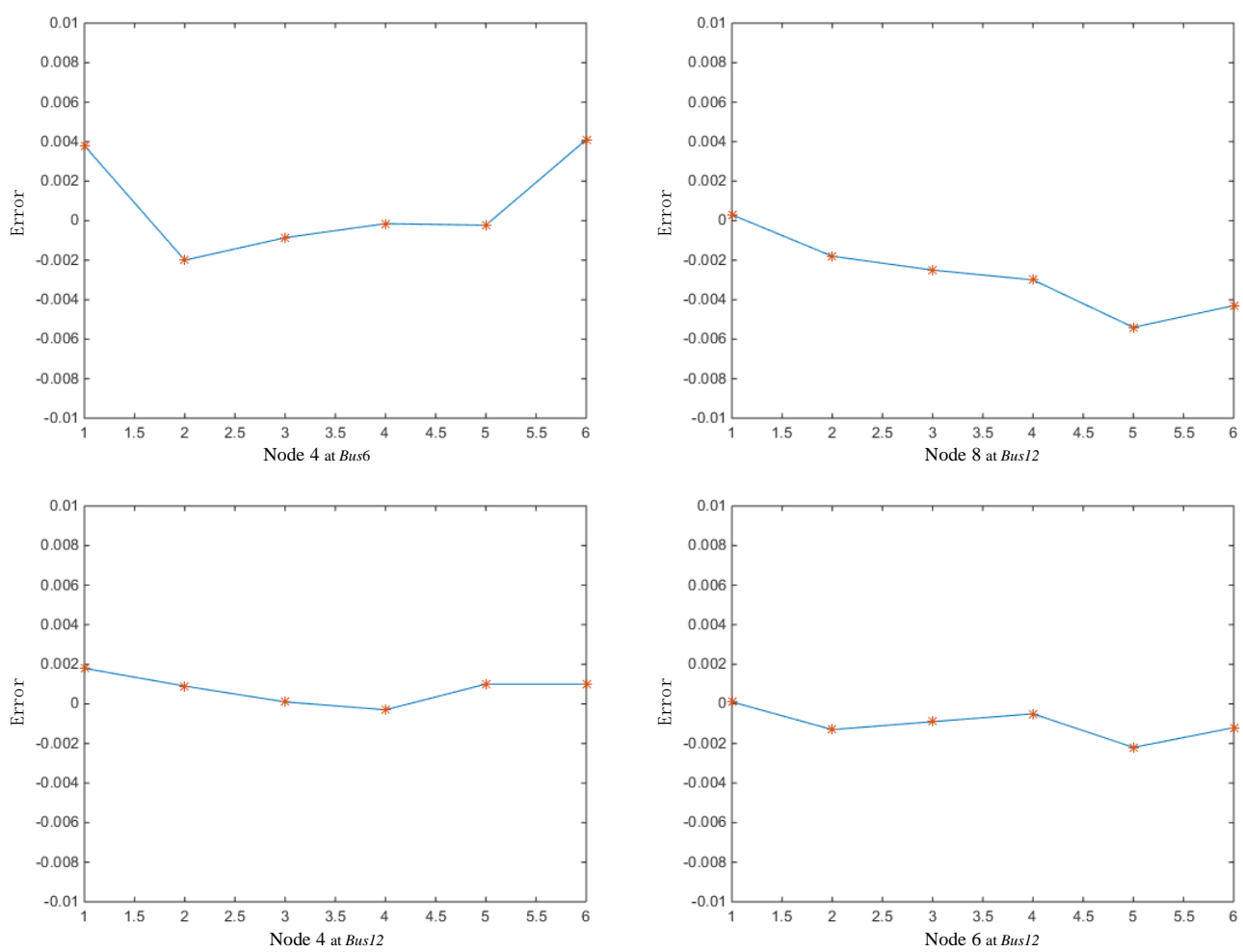

Figure 13. Errors between predicted and simulated voltages.

The prediction results and simulation results of the voltages of the connected nodes are compared under different short-circuit conditions which are shown in Figure 13. It shows that the maximum error of the proposed method is 0.0054 p.u., and the inverter output mode can be selected selection accurately under the LVRT control strategy. Therefore, in the fault calculation of the distribution network, the voltage prediction method based on deep learning proposed in this paper can be used to accurately provide the output mode of the inverter LVRT control strategy.

\subsection{Analysis of Distribution Network Faults Calculation Considering Voltage Prediction}

The IEEE 13 bus system is still used in this section, and the short-circuit point is Bus13. First, the voltages of connected nodes are predicted. Then the short-circuit calculated results are compared with simulated results from DIgSILENT 15.2, which are shown in Table 5. The calculation errors of two groups of data are shown in Figure 12.

Table 5. Comparison of fault calculation results and simulation results.

\begin{tabular}{|c|c|c|c|c|c|c|c|c|c|}
\hline \multirow[b]{2}{*}{ Node } & \multicolumn{2}{|c|}{ Fault Calculation Results } & \multicolumn{2}{|c|}{$\begin{array}{c}\text { DIgSILENT Simulation } \\
\text { Results }\end{array}$} & \multirow[b]{2}{*}{ Node } & \multicolumn{2}{|c|}{ Fault Calculation Results } & \multicolumn{2}{|c|}{$\begin{array}{c}\text { DIgSILENT Simulation } \\
\text { Results }\end{array}$} \\
\hline & $\begin{array}{c}\text { Voltage } \\
\text { Amplitude } \\
(\mathbf{k V )}\end{array}$ & $\begin{array}{l}\text { Voltage } \\
\text { Phase } \\
\text { Angle } \\
\text { (deg) }\end{array}$ & $\begin{array}{c}\text { Voltage } \\
\text { Amplitude } \\
(\mathbf{k V})\end{array}$ & $\begin{array}{l}\text { Voltage } \\
\text { Phase } \\
\text { Angle } \\
\text { (deg) }\end{array}$ & & $\begin{array}{c}\text { Voltage } \\
\text { Amplitude } \\
(\mathbf{k V})\end{array}$ & $\begin{array}{l}\text { Voltage } \\
\text { Phase } \\
\text { Angle } \\
\text { (deg) }\end{array}$ & $\begin{array}{c}\text { Voltage } \\
\text { Amplitude } \\
(\mathbf{k V )}\end{array}$ & $\begin{array}{l}\text { Voltage } \\
\text { Phase } \\
\text { Angle } \\
\text { (deg) }\end{array}$ \\
\hline 1 & 10.50000 & 0.00000 & 10.50000 & 0.00000 & 8 & 4.53172 & -3.7971 & 4.55414 & -3.65907 \\
\hline 2 & 10.26249 & -0.17362 & 10.26418 & -0.16980 & 9 & 4.53322 & -3.92135 & 4.55601 & -4.00023 \\
\hline 3 & 9.00014 & -1.19956 & 9.00792 & -1.17349 & 10 & 2.63696 & -7.42896 & 2.65624 & -7.20942 \\
\hline 4 & 8.06503 & -2.16887 & 8.07757 & -2.21097 & 11 & 2.63907 & -7.90213 & 2.65839 & -7.81251 \\
\hline 5 & 8.06487 & -2.23012 & 8.07801 & -2.30012 & 12 & 1.61623 & -5.16154 & 1.62805 & -4.94201 \\
\hline 6 & 7.07495 & -3.33691 & 7.09007 & -3.26921 & 13 & 0.36614 & 15.58863 & 0.36909 & 15.80816 \\
\hline 7 & 6.28679 & -3.46117 & 6.30419 & -3.37839 & & & & & \\
\hline
\end{tabular}


It can be seen from Table 5 and Figure 14 that the maximum calculation error of the voltages is $22.321 \mathrm{~V}$. It is in the allowable range and meets the requirements of general fault calculation.

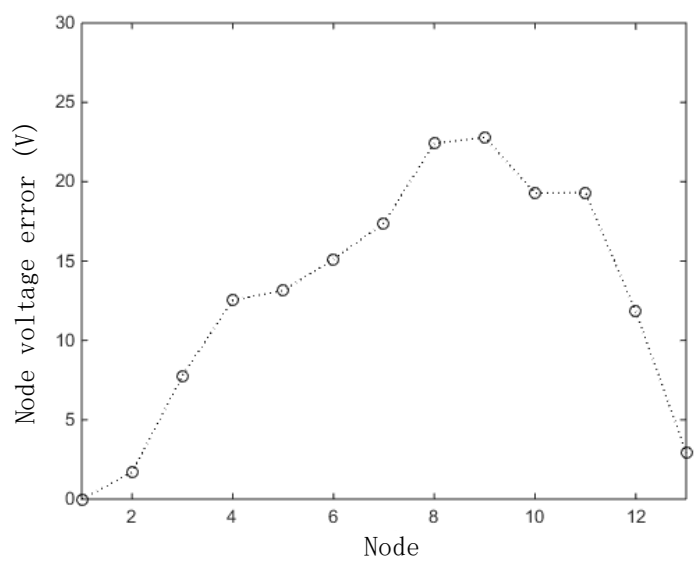

Figure 14. Difference diagram between fault calculation results and simulation results.

\section{Conclusions}

This paper analyzes the relationship among the connected node voltage, system rated capacity $(S)$, network short-circuits impedance $(Z)$, and distributed power output $(P)$. The following are some major findings:

(1) Based the deep learning, a BP neural network model with a linear activation function is established to train the simulated datasets. Then the predicted results under different short-circuit scenarios are compared with DIgSILENT output. The proposed method can more accurately predict the voltage of the connected node. The effectiveness of the proposed method is verified.

(2) Based on the prediction of the voltage, the IIDG output mode during fault calculation can be selected to meet LVRT accurately. Compared with the traditional fault calculation, the proposed method can simplify the calculation process.

In future studies, the relationship between the positive and negative sequence voltage of the connected nodes and $S, Z$, and $P$ will be considered to realize the LVRT control targets of negative sequence current injection, negative sequence voltage compensation, and reactive power support under asymmetric faults.

Author Contributions: Conceptualization, H.L. and C.Z.; methodology, H.L. and K.P.; software, C.Z. and H.L.; validation, K.P., H.L. and C.Z.; formal analysis, H.L. and C.Z.; writing-original draft preparation, H.L. and K.P.; writing-review and editing, K.P. and C.Z.; project administration, K.P.; funding acquisition, K.P., Y.C. and B.X. All authors have read and agreed to the published version of the manuscript.

Funding: This research was funded by National Key Research and Development Program of China, grant number 2016YFB0900600.

Institutional Review Board Statement: Not applicable.

Informed Consent Statement: Informed consent was obtained from all subjects involved in the study.

Data Availability Statement: Not applicable.

Conflicts of Interest: The authors declare no conflict of interest. 


\section{References}

1. Kong, X.; Zhang, Z.; Yin, X.; Wang, F.; He, M. Study on fault current characteristics and fault analysis method of power grid with inverter interfaced distributed generation. Proc. CSEE 2013, 33, 65-74.

2. Peng, K.; Zhang, C.; Xu, B.Y.; Chen, Y.; Chen, J.J.; Zhao, X.S. Key issues of fault analysis on distribution system with high-density dis-tributed generations. Autom. Electr. Power Syst. 2017, 41, 184-192.

3. Shi, X.; Zhang, H.; Wei, C.; Li, Z.; Chen, S. Fault modeling of IIDG considering inverter's detailed characteristics. IEEE Access 2020, 8, 183401-183410. [CrossRef]

4. Dai, Z.; Chuan, L.I.; Jiao, Y. Low-voltage ride through model of inverter-interfaced distributed generator and its application to fault analysis of distribution network. Proc. CSU-EPSA 2018, 30, 16-23.

5. Eskandari, M.; Li, L.; Moradi, M.H.; Siano, P.; Blaabjerg, F. Optimal voltage regulator for inverter interfaced distributed generation units part II: Application. IEEE Trans. Sustain. Energy 2020, 99, 2825-2835. [CrossRef]

6. Lu, X.; Yang, D.; Wang, Q.; Yin, Z. Modeling and simulation of voltage sag assessment for distribution network based on total coverage of nodes. In IOP Conference Series: Earth and Environmental Science; IOP Publishing: Bristol, UK, 2021; Volume 772, p. 012023.

7. Rasmussen, T.B.; Yang, G.; Nielsen, A.H. Interval estimation of voltage magnitude in radial distribution feeder with minimal data acquisition requirements. Int. J. Electr. Power Energy Syst. 2019, 113, 281-287. [CrossRef]

8. Ding, K.; Hu, P.; Li, W.; Qian, Y.M.; Wang, Y.; Xiao, X.Y. Prediction of voltage sag economic losses based on information distribution and diffusion theory. In Proceedings of the 19th International Conference on Harmonics and Quality of Power, Dubai, United Arab Emirates, 6-7 July 2020.

9. Ji, L.; Shi, J.; Hong, Q.; Fu, Y.; Chang, X.; Cao, Z.; Mi, Y.; Li, Z.; Booth, C. A multi-objective control strategy for three phase grid-connected inverter during unbalanced voltage sag. IEEE Trans. Power Deliv. 2020, 99, 1. [CrossRef]

10. Bollen, M.H.J.; Tayjasanant, T.; Yalcinkaya, G. Assessment of the number of voltage sags experienced by a large industrial customer. IEEE Trans. Ind. Appl. 2002, 33, 1465-1471. [CrossRef]

11. Chao, Z.; Lijun, T. An optimum allocation method of voltage sag monitoring nodes based on particle swarm opti-mization algorithm. Trans. China Electrotech. Soc. 2014, 29, 181-187.

12. Dai, S.; Han, M.; Yan, W. Voltage sag assessment for distribution network containing distributed gen-eration. Power Syst. Technol. 2011, 35, 145-149.

13. Yaoyao, H.; Caixi, W.; Qifa, X.; Aoyang, H.A. Method to predict probability density of medium-term power load considering temperature factor. Power Syst. Technol. 2015, 39, 176-181.

14. Shuai, Z.; Shen, C.; Yin, X.; Liu, X.; Shen, Z.J. Fault analysis of inverter-interfaced distributed generators with different control schemes. IEEE Trans. Power Deliv. 2017, 33, 1223-1235. [CrossRef]

15. Wang, Q.; Zhou, N.; Ye, L. Fault analysis for distribution networks with current-controlled three-phase inverter-interfaced distributed generators. IEEE Trans. Power Deliv. 2015, 30, 1532-1542. [CrossRef]

16. Xu, Y.; Mu, L.; Zhang, F.; Mou, Z.; Zhu, J. Analysis of the Fault Characteristics of Microgrid with Inverter-Interfaced Distributed Generators. In Proceedings of the 2019 IEEE 8th International Conference on Advanced Power System Automation and Protection (APAP), Xi'an, China, 21-24 October 2019.

17. Wang, Y.; Chen, Q.; Huang, X.; Song, Q. Faulty feeder detection based on space relative distance for compensated distribution network with IIDG injections. IEEE Trans. Power Deliv. 2020, 32, 453-461.

18. Guo, W.; Mu, L.; Zhang, X. Fault models of inverter-interfaced distributed generators within a low-voltage microgrid. IEEE Trans. Power Deliv. 2017, 1, 1. [CrossRef]

19. Li, B.; Peng, S.; Peng, J.; Huang, S.; Zheng, G. Wind power probability density forecasting based on deep learning quantile regression model. Electr. Power Autom. Equip. 2018, 38, 15-20.

20. Hu, W.; Zheng, L.; Min, Y.; Dong, Y.; Yu, R.; Wang, L. Research on power system transient stability assessment based on deep learning of big data technique. Power Syst. Technol. 2017, 41, 3140-3146.

21. Yin, X.; Yan, J.; Liu, Y.; Qiu, C.G. Deep learning based transient stability assessment and severity grading. Electr. Power Autom. Equip. 2018, 289, 71-76.

22. He, Y.; Xu, Q.; Yang, S.; Yu, B. A power load probability density forecasting method based on rbf neural network quantile. Proc. CSEE 2013, 33, 93-98.

23. Han, B.; Li, H.; Wang, G.; Zeng, D.; Liang, Y. A virtual multi-terminal current differential protection scheme for distribution networks with inverter-interfaced distributed generators. IEEE Trans. Smart Grid 2017, 9, 5418-5431. [CrossRef]

24. Yin, X.; Li, X.; Zhang, Y.; Zhang, T.; Lu, C.; Ai, Q.; Li, Z.; Sun, Z. A survey of deep learning and its application in distribution network. In Proceedings of the 2020 International Conference on Artificial Intelligence in Information and Communication, Tianjin, China, 16 April 2020.

25. Dong, D.; Sheng, Z.; Yang, T. Wind power prediction based on recurrent neural network with long short-term memory units. In Proceedings of the 2018 International Conference on Renewable Energy and Power Engineering, Toronto, ON, Canada, 24-26 November 2018. 
26. Tao, Y.; Chen, H.; Qiu, C. Wind power prediction and pattern feature based on deep learning method. In Proceedings of the 2014 IEEE PES Asia-Pacific Power and Energy Engineering Conference (APPEEC), Brisbane, Australia, 15-18 November 2015.

27. Xiaosheng, P.; Bo, W.; Fan, Y.; Gaofeng, F.; Zheng, W.; Kai, C. A deep learning approach for wind power prediction based on stacked denoising auto encoders optimized by bat algorithm. In Proceedings of the 2018 China International Conference on Electricity Distribution (CICED), Tianjin, China, 17-19 September 2018. 